\title{
Immunohistochemical Study Using Monoclonal VE1 Antibody Can Substitute the Molecular Tests for Apprehension of BRAF V600E Mutation in Patients with Non-small-Cell Lung Carcinoma
}

\author{
Hadeel Abdul Elah Karbel $\mathbb{D}^{,},{ }^{1}$ Sura Salman Ejam, ${ }^{2}$ and Ali Zaki Naji ${ }^{3}$ \\ ${ }^{1}$ Pathology Dept. Hammurabi College of Medicine, University of Babylon, Iraq \\ ${ }^{2}$ Pathology Dept. College of Medicine, University of Babylon, Iraq \\ ${ }^{3}$ Basic Science Dept. College of Dentistry, Babylon University, Iraq \\ Correspondence should be addressed to Hadeel Abdul Elah Karbel; hadeelkerbel1974@gmail.com
}

Received 7 August 2019; Revised 8 October 2019; Accepted 14 October 2019; Published 5 November 2019

Academic Editor: Silvia Cantara

Copyright (c) 2019 Hadeel Abdul Elah Karbel et al. This is an open access article distributed under the Creative Commons Attribution License, which permits unrestricted use, distribution, and reproduction in any medium, provided the original work is properly cited.

\begin{abstract}
In patients with non-small-cell lung carcinoma (NSCLC), the analysis of BRAF V600E mutation has become more and more applied since the introduction of many mutation-targeted medications. In this regard, the advantage of immunohistochemistry (IHC) as a reliable diagnostic test substitute to other molecular studies has not been approved yet. Objective. To examine the dependability of using immunohistochemical method utilizing monoclonal VE1 antibody in the detection of BRAF V600 E mutation in patients with non-small-cell lung carcinoma and compare the results there with that of polymerase chain reaction (SSCP-PCR). Materials and Methods. We retrospectively identified 53 patients of whom their histopathological diagnosis was non-small-cell carcinoma of different types. Evaluation of BRAF V600E mutation was assessed using polymerase chain reaction (SSCP-PCR) and IHC using VE1 antibody. This approach was applied to all cases under the study. Results. Among the 53 NSCLC samples, only 5 (9.3\%) cases harbored BRAF V600E mutation, $80 \%$ were of adenocarcinoma type, and the rest (20\%) was of squamous cell carcinoma. IHC analysis for VE1 was positive in 4 out of 5 (80\%) BRAF-mutated tumors and negative in all nonmutated BRAF V600 E NSCLC. Conclusion. Our results revealed that VE1 antibody IHC analysis is a promising technique that can be used to detect BRAF V600-mutated NSCLC with relatively high specificity and sensitivity and might become a potential alternative to the current molecular biological methods that are in use for this purpose.
\end{abstract}

\section{Introduction}

For considerable decades, lung cancer has been considered the major outstanding cause of cancer-related mortality globally [1].

The GLOBOCAN database revealed that lung cancer is responsible for about $19 \%$ of all cancer-causing death worldwide in 2019 [2].

Broadly, the WHO classification (2015) of tumors of the lung, pleura, thymus, and heart has been subclassified into two major types of the epithelial tumors of the lung: small-cell lung cancer (SCLC) which accounts for 15\% of lung carcinomas and non-small-cell lung cancers (NSCLs) which account for the $85 \%$ remainder of all lung carcino- mas $[3,4]$. Almost two-thirds of those patients are diagnosed at progressive stages of the disease; thus, their therapeutic options are limited with poor prognosis and low survival rate $[5,6]$. However, the overall survival of such patients with advanced disease stage can be enhanced by rapid administration of target-specific drugs against sure genetic changes in either EGFR or ALK genes. Furthermore, several therapeutics target specific somatic mutations involving different oncogenes $[7,8]$, like $v$-raf murine sarcoma viral oncogene homolog B (BRAF) mutation. These mutations will play vital role in predicting patient outcome and response to target medications $[9,10]$.

The BRAF codes for a nonreceptor serine/threonine kinase, in which the latter is an important member of the 
RAS/RAF/MEK mitogen-activated protein kinase (MAPK). Mutation in BRAF would subsequently result in pathway alteration and sustained kinase activity which are one of the corner stones in the process of carcinogenesis [11, 12].

The bulk of these mutations are caused by hotspot transversion mutation at exon 15 , which leads to amino acid substitution of V600 E [13].

BRAF V600E mutation has been established in various types of cancers, like melanoma, papillary thyroid carcinoma, and metastatic colorectal adenocarcinoma with a frequency of mutation at about 50\%, 45\%, and 9\%, respectively [14, 15]. While previous studies have shown that the prevalence of BRAF mutation in lung carcinoma is approximately 2$4 \%[8,10,16]$.

The diagnosis of lung carcinoma is frequently achieved in small-sized biopsies, obtained either by bronchoscopy or CTguided/echo-guided routes, thus dealing with such small biopsies must be optimized in order to reach the final diagnosis taking into consideration the current ancillary techniques which can be performed in FFPE tissue biopsies that allow both histopathological and immunohistochemical features to be characterized, as well as analysis and extraction of DNA for further molecular studies [17].

In this study, we aimed to study the pervasiveness of BRAF V600E mutation in biopsies of NSCLC patients using SSCP-PCR in comparison to immunohistochemical study for the same gene.

\section{Materials and Methods}

This is a retrospective study carried out from December 2017 to March 2019. We include patients with NSCLC from several private labs and Teeba Respiratory Center in Hilla city, Babylon province. The analytic data of 53 patients with NSCLC were retrieved; however; we could not obtain all the clinical data for some patients like the stage of the disease; formalin-fixed paraffin-embedded (FFPE) tissue samples for those patients were also collected; all the results were reviewed by three expert histopathologists and final confirmation of the diagnosis was done. While in cases of poorly differentiated tumors, we needed to use ancillary IHC to reach the final diagnosis. A similar number (53) of normal lung tissues was also included and used as control samples for the PCR study.

Ethical clearance was attained from the Scientific committee of the Hamourabi College of Medicine, University of Babylon.

\section{Molecular Study}

3.1. FFPE Tissue DNA Extraction. FFPE tissue section samples were extracted using NEXprep ${ }^{\mathrm{TM}}$ FFPE Tissue Kit, Genes Laboratories, Korea. The extraction was achieved according to the manufacturer's protocol. In brief, xylene was used to remove the paraffin waxes and was washed out by absolute ethanol. Then, genomic DNA was extracted with Proteinase $\mathrm{K}$, and aliquots from the extracted DNA samples were quantified using a NanoDrop spectrophotometer. Finally, the samples were placed in $-20^{\circ} \mathrm{C}$ for further use in SSCPPCR experiments.

3.2. Single-Strand Conformation Polymorphism (SSCP). SSCP-PCR was performed for detection of V600E mutation in exon 15 of the BRAF gene from the lung carcinoma and normal lung tissue samples. The method was carried out according to Kobayashi et al. [18]. The BRAF gene exon 15 primers include forward primers $\left(5^{\prime}\right.$-CCTAAACTCT TC ATAATGCTTGCTC-3) and reverse primer $\left(5^{\prime}\right.$-TTAATC AGTGGAAAAAT AGCCTCAA-3) provided by Macrogen, Korea. The PCR master mix was prepared according to the user manual. (AccuPower ${ }^{\circledR}$ PCR Pre Mix kit, Bioneer, Korea). The PCR tubes contain a pellet consisting of (Taq DNA polymerase $1 \mathrm{U}$, Tris- $\mathrm{HCl}(\mathrm{pH} 9.0) 10 \mathrm{mM}, \mathrm{KCl}$ $30 \mathrm{mM}$, stabilizer, $\mathrm{MgCl} 21.5 \mathrm{mM}$, dNTPs $250 \mu \mathrm{M}$, and tracking dye). The preparation of the master mix was achieved according to the protocol provided by the kit. The PCR assay was achieved to a final reaction volume of $20 \mu \mathrm{l}$ consisting of $5 \mu \mathrm{l}$ of DNA , $1.5 \mu \mathrm{l}$ of $10 \mathrm{pmol}$ of each forward primer and reverse primer mixed together, and then the volume was completed to $20 \mu \mathrm{l}$ with deionized water. The reaction mixture was then mixed, briefly vortexed, and placed in the thermocycler (T100 Thermal cycler, Bio-Rad, USA) with the subsequent thermal conditions:

(1) Initial denaturation temperature was $94^{\circ} \mathrm{C}$ for $5 \mathrm{~min}$

(2) 35 cycles at denaturation $94^{\circ} \mathrm{C}$ for $30 \mathrm{~s}$

(3) Annealing was achieved at $58^{\circ} \mathrm{C}$ for $30 \mathrm{~s}$

(4) Extension was $72^{\circ} \mathrm{C}$ for $1 \mathrm{~min}$

(5) Final extension was $72^{\circ} \mathrm{C}$ for $5 \mathrm{~min}$

After that, the SSCP for BRAF mutations were done by denaturing PCR products through incubation at $95^{\circ} \mathrm{C}$ for $6 \mathrm{~min}$; then, the specimens were immediately placed on ice. After that, the quality and quantity of PCR amplicons were then confirmed with $1 \%$ agarose gel electrophoresis with subsequent visualization by UV illumination.

3.3. Immunohistochemistry. The clinical specimens used were surgically resected biopsies $(n=38)$ and bronchoscopically obtained biopsies $(n=15)$. From each tissue block, two sections were stained with hematoxylin and eosin $(\mathrm{H}$ and $\mathrm{E})$ method and immunohistochemical polydetector plus horseradish peroxidase staining method using monoclonal mouse antihuman BRAF V600 protein, ready-to-use, Bio SB, Clone L50-823, USA. A tumor was considered positive for V600E immunostaining when uniform signal was detected in the cytoplasm of at least $50 \%$ of the tumor cells and the intensity scoring graded as zero (negative), +1(weak cytoplasmic signal), +2 (moderate cytoplasmic signal), and +3 (strong cytoplasmic signal) according to Sasaki et al. [19]. Positive control from papillary thyroid carcinoma tissues was concerned in every run. Figure 1(d).

3.4. Statistical Analysis. Statistical analysis was accomplished using SPSS version 20. Absolute variables were presented as 


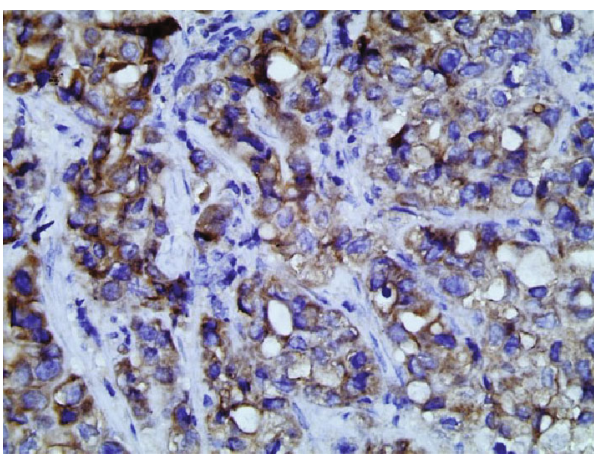

(a)

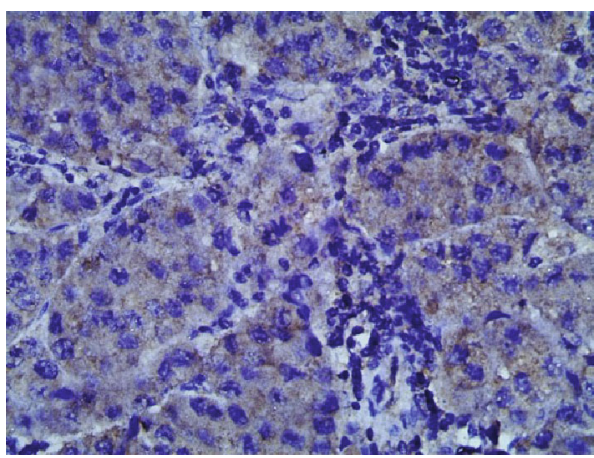

(c)

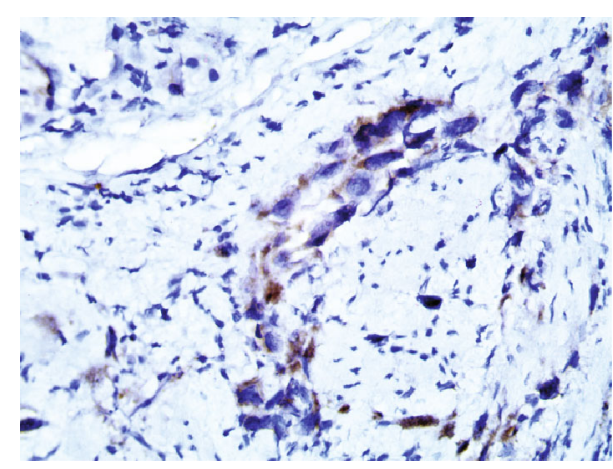

(b)

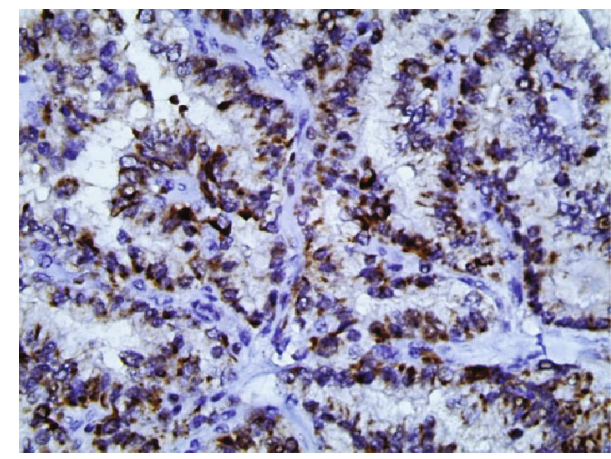

(d)

FIgURE 1: Immunohistochemical pathological examination of NSCLC using VE1 antibody. (a) Poorly differentiated adenocarcinoma with strong cytoplasmic staining $($ score +3$) \times 200$. (b) Poorly differentiated adenocarcinoma with moderate cytoplasmic staining $($ score +2$) \times 200$. (c) Moderately differentiated adenocarcinoma with weak cytoplasmic staining (score +1$) \times 200$. (d). Positive control papillary carcinoma of the thyroid with strong cytoplasmic staining $\times 200$.

frequencies and percentages. A $p$ value of equal or less than 0.05 was selected as a significant value.

\section{Results}

The clinical aspects for patients with NSCLC involved in this study is summarized in Table 1 . Out of 53 cases of NSCLC, 5 (9.3\%) were shown to have BRAF V600E mutation in exon 15 in comparison to 53 samples of normal lung tissues which revealed only the wild type of the gene by using SSCP-PCR (Figure 2).

The particular clinical features for patients with mutant BRAF are mentioned in Table 2. Regarding the histology of NSCLC with mutant BRAF gene, 4 cases (80\%) were adenocarcinoma, while only one case $(20 \%)$ was squamous cell carcinoma.

BRAF wild-type gene was detected in 48 (90.6\%) of patients' samples with NSCLC, 30 were males, 18 were females with age ranging between 45 and 85 years.

There was no important association between BRAF wild-type and mutant cases concerning the gender, age, and histopathological types of NSCLC $(p>0.05)$.

An immunohistochemical study with VE1 monoclonal antibodies revealed positive results in 4 (80\%) out of 5 cases with mutant BRAF V600E as demonstrated by SSCP-PCR. Furthermore, our results show a significant association between IHC results and PCR results for the detection of
TABLE 1: Clinicopathological characteristics of patients with nonsmall-cell lung carcinoma (no. $=53$ ).

\begin{tabular}{lc}
\hline & No. $(\%)$ \\
\hline Gender & $30(56.6 \%)$ \\
Male & $23(43.4 \%)$ \\
Female & \\
Age & $12(22.6 \%)$ \\
$45-55$ & $19(35.9 \%)$ \\
$56-65$ & $17(32.1 \%)$ \\
$66-75$ & $5(9.4 \%)$ \\
$76-85$ & \\
Histological types & $27(50.9 \%)$ \\
ADENO CA & $22(41.5 \%)$ \\
SQUAMOUS CA & $2(3.8 \%)$ \\
ADENO/SQ CA & $2(3.8 \%)$ \\
Large cell CA & \\
Differentiation & $12(22.6 \%)$ \\
Well & $23(43.3 \%)$ \\
Moderately & $18(33.9 \%)$ \\
Poorly &
\end{tabular}

ADENO CA: adenocarcinoma; SQUAMOUS CA, squamous cell carcinoma: ADENO/SQ CA, adeno-squamous carcinoma. 


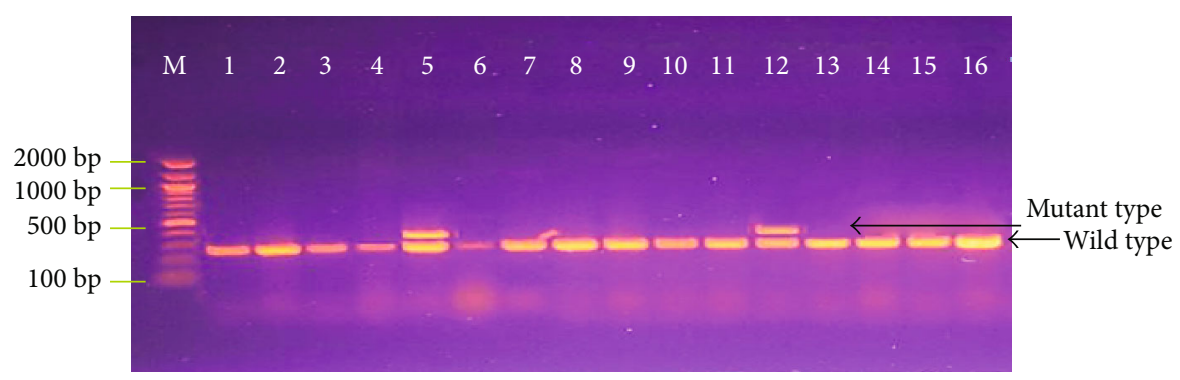

FIGURE 2: Agarose gel electrophoresis image that show the SSCP-PCR product analysis for the detection of V600E mutation in exon 15 of BRAF gene from NSCLC and normal lung tissue samples where M is marker (2000-100 bp), lanes 1-4, 6-11, and 14-16 are wild-type, and where lanes 5 and 12 are V600E mutation.

TABLE 2: Clinicopathological characteristics of patients with mutant BRAF V600E tumors (no. = 5).

\begin{tabular}{|c|c|c|c|c|c|c|c|}
\hline Patient & BRAF mutation & IHC VE1 & IHC intensity scoring & Age & Sex & Histological type & Differentiation \\
\hline 1 & Positive & Positive & +3 & 61 & $\mathrm{M}$ & Adeno $\mathrm{Ca}$ & Poorly diff. \\
\hline 2 & Positive & Positive & +1 & 65 & $\mathrm{~F}$ & Adeno Ca & Poorly diff. \\
\hline 3 & Positive & Negative & Zero & 62 & M & Squamous $\mathrm{Ca}$ & Moderate diff. \\
\hline 4 & Positive & Positive & +2 & 59 & M & Adeno Ca & Poorly diff. \\
\hline 5 & Positive & Positive & +1 & 67 & $\mathrm{~F}$ & Adeno $\mathrm{Ca}$ & Moderate diff. \\
\hline
\end{tabular}

F, female; M, male; adeno Ca, adenocarcinoma; squamous $\mathrm{Ca}$, squamous carcinoma; diff, differentiated.

BRAF V600E mutational status in patients with NSCLC ( $p$ value $=0.0001)$ with a chi-square value $=41.535$. Table 3 .

Comparison of IHC results with that of PCR study, declared sensitivity of $97.9 \%$ and specificity of $100 \%$.

The immunohistochemical results were reviewed and validated by three pathologists with $100 \%$ concordances which were considered positive if homogenous intracytoplasmic staining was shown in carcinoma cells solely. The intensity of immunohistochemical results was scored from 1-3 consequently, with no significant association with the type of the tumors and degree of differentiation $(p>0.05)$ (Figure 1(a)-(c)).

\section{Discussion}

The central objective of this study was to explore the possibility of utilizing monoclonal VE1 antibody immunohistochemical test as a surrogate for the presently used molecular techniques in the detection of BRAF V600E mutation in NSCLC patients. Toward this, we tend to start with testing molecular mutation of BRAF V600E utilizing SSPC-PCR technique. We found BRAF V600E mutations in $9.3 \%$ of the patients; this is often comparatively higher than those reported in other series $(0.8 \%-4.9 \%)[10,16$, $18,20,21,22]$, whereas a study carried out by Ilie et al. [17] revealed 9\% BRAF mutation which is nearly similar to our results. It is worth mentioning that their study was achieved in EGFR, K RAS, PI3KCA, HER2, and EML4ALK wild-type adenocarcinoma only. Nonetheless, we included all types of NSCLC in our samples and only 50.9\% were of adenocarcinoma type.

Similar to other studies $[10,16,23]$, BRAF V600E mutation is more prevalent in adenocarcinoma type (80\%) with exceptionally one case (20\%) of squamous cell carcinoma. Most of these cases were of high-grade, poorly differentiated solid type, and this could explain the relatively higher frequency of BRAF mutation in our study. These results are similar to Yousem et al.'s [24] and Kobayashi et al.'s [18]. findings which demonstrated that the majority of BRAFmutated NSCLC was of high grade and poor prognosis. Chen et al. [20] in their systemic review and meta-analysis for patients with mutant BRAF NSCLC found that Asians have a somewhat higher tendency of harboring BRAF alteration than others; however, this association is weak and of no statistical significance.

Our results that there have been no vital association between prevalence of BRAF mutation and the patient gender $(p>0.05)$ is incontestable, with similar results demonstrated by Cardarella et al. [25], Ilie et al. [17], and Chen et al. [20] Such association was previously observed in female patients with BRAF mutant colorectal carcinoma $[26,27]$.

Then, we went on emulating BRAF mutation using IHC methodology. We noted that VE1 monoclonal antibody achieved high concurrence rates with the molecular practice $(p<0.05)$. Similar concordance pattern was reported by Ilie et al. [17], Sasaki et al. [19], and Gow et al. [28] who found that IHC with VE1 clone is a very sensitive and specific method for the detection of mutant BRAF gene in lung adenocarcinoma. Likewise, Luk et al. [21] demonstrated that BRAF IHC was positive in two out of three cases with V600E gene alteration, and their results were steady with the Sequenom massARRAY platform results.

Indeed, immunohistochemical analysis for VE1 mutation was recommended as a predictable methodology for detection of BRAF V600E mutation in alternative tumors like 
TABLE 3: The association of IHC of BRAF VE in patients of NSCLC with mutant type BRAF V600E by SSCP-PCR.

\begin{tabular}{lcccc}
\hline & & \multicolumn{2}{c}{ IHC BRAF VE1 } & Negative \\
& & Positive & $1(1.9 \%)$ & $5(9.4 \%)$ \\
BRAF V600E SSCP-PCR & Mutant gene & $4(7.5 \%)$ & $48(90.6 \%)$ & $48(90.6 \%)$ \\
Total & Wild gene & $0(0 \%)$ & $49(92.5 \%)$ & $53(100 \%)$ \\
\hline
\end{tabular}

$p$ value $=0.0001$. Chi-square value $=41.535$.

melanoma [29], papillary carcinoma of the thyroid [30, 31], and colorectal carcinoma [32].

Given the very fact that BRAF V600E mutational status is clinically of great prognostic value, determination of this mutation has become increasingly performed as an adjunct to histopathological study, since there are many BRAF pathway-targeting agents in clinical advancement and trials, such as XL281, selumetinib, and PLX4032 [33, 34].

For BRAF gene mutation in NSCLC detection, analysis was carried out by utilizing molecular methods including DNA extraction from FFPE biopsies [35], such methods can lead to depletion of tissue samples or the samples themselves are already not sufficient for such molecular approach because most of the biopsies that had been used in the diagnosis are bronchial or core needle transthoracic specimens. Consequently, the adoption of another specific and sensitive method for the detection of BRAF V600E gene mutation on these tissue sections may grant the conservation of the samples and also provide low-charge procedure.

Several drawback points were also reported in the molecular analytic techniques $[36,37]$, used for BRAF gene mutation in metastatic brain tumors. These techniques revealed negative results as compared to IHC which was capable of identifying a small portion of BRAF V600E-expressing carcinoma cells. Such inconsistency was interpreted by Ilie et al. [38] due to hyper fixation of DNA, existence of necrotic tumor areas, or low frequency of BRAF-mutated cells, which in turn lead to a decrease in efficiency of molecular techniques for identification of BRAF mutation. In our study, only one case was IHC negative for VE1, and this could be due to several factors including improper tissue fixation and heterogenous expression of the antigen which could be overcome by staining multiple sections from the same tissue samples; however, this is not always possible in small tissue biopsies.

Katerina et al. [30] in their study for the foremost impact preanalytical conditions for the IHC detection of BRAF V600E (VE1) antibody on colorectal and papillary thyroid carcinoma conclude that the most proper tissue fixation ought to be done within 2 hours of tissue collection for 12-24 hours in 10\% neutral buffered formalin.

\section{Conclusion}

The current study provides new data concerning BRAF immunohistochemical technique as a reliable methodology for the analysis of the mutational status of BRAF V600E in NSCLC patients especially with the recent development of mutation-specific BRAFV600E monoclonal antibodies which made it a rapid and cost-effective test for those patients.

\section{Data Availability}

The data findings of this research have to be seen in light of some restrictions including the small sample size of the study group, retrospective design of the study, and lack of patient follow-up for detection of the survival rate for those with mutant BRAF V600E NSCLC.

\section{Conflicts of Interest}

The authors declare that they have no conflicts of interest.

\section{Acknowledgments}

We would like to express our forthright thanks to Dr. Al Humairi IA. (Babylon University, Hamourabi College of Medicine) for her technical supervision and support.

\section{References}

[1] L. A. Torre, R. L. Siegel, and A. Jemal, "Lung cancer statistics," Advances in Experimental Medicine and Biology, vol. 893, pp. 1-19, 2016.

[2] J. Ferlay, I. Soerjomataram, R. Dikshit et al., "Cancer incidence and mortality worldwide: sources, methods and major patterns in GLOBOCAN 2012," International Journal of Cancer, vol. 136, no. 5, pp. E359-E386, 2015.

[3] W. D. Travis, E. Brambilla, A. G. Nicholson et al., "The 2015 World Health Organization classification of lung tumors: impact of genetic, clinical and radiologic advances since the 2004 classification," Journal of Thoracic Oncology, vol. 10, no. 9, pp. 1243-1260, 2015.

[4] W. D. Travis, E. Brambilla, A. P. Burke, and A. G. Nicholson, WHO classification of tumors of the lung, pleura, thymus and heart, Lyon: international agency of research on cancer, 2015.

[5] K. D. Miller, L. Nogueira, A. B. Mariotto et al., "Cancer treatment and survivorship statistics, 2019," CA: A Cancer Journal for Clinicians, vol. 69, no. 5, pp. 363-385, 2019.

[6] G. D. Goss and J. N. Spaans, "Epidermal growth factor receptor inhibition in the management of squamous cell carcinoma of the lung," The Oncologist, vol. 21, no. 2, pp. 205-213, 2016.

[7] L. Cheng, R. E. Alexander, G. T. MacLennan et al., "Molecular pathology of lung cancer: key to personalized medicine," Modern Pathology, vol. 25, no. 3, pp. 347-369, 2012.

[8] S. A. Yousem, "Role of molecular studies in the diagnosis of lung adenocarcinoma," Modern Pathology, vol. 25, no. S1, pp. S11-S17, 2012. 
[9] A. T. Shaw, D. W. Kim, K. Nakagawa et al., "Crizotinib versus chemotherapy in advanced ALK-positive lung cancer," The New England Journal of Medicine, vol. 368, no. 25, pp. 23852394, 2013.

[10] A. Marchetti, L. Felicioni, S. Malatesta et al., "Clinical features and outcome of patients with non-small-cell lung cancer HarboringBRAFMutations," Journal of Clinical Oncology, vol. 29, no. 26, pp. 3574-3579, 2011.

[11] M. J. Garnett and R. Marais, "Guilty as charged: B-RAF is a human oncogene," Cancer Cell, vol. 6, no. 4, pp. 313-319, 2004.

[12] H. Davies, G. R. Bignell, C. Cox et al., "Mutations of the BRAF gene in human cancer," Nature, vol. 417, no. 6892, pp. 949954, 2002.

[13] E. R. Cantwell-Dorris, J. J. O'Leary, and O. M. Sheils, "BRAFV600E: implications for carcinogenesis and molecular therapy," Molecular Cancer Therapeutics, vol. 10, no. 3, pp. 385-394, 2011.

[14] J. A. Sosman, K. B. Kim, L. Schuchter et al., "Survival in BRAF V600-mutant advanced melanoma treated with vemurafenib," The New England Journal of Medicine, vol. 366, no. 8, pp. 707714, 2012.

[15] M. Xing, "BRAF mutation in thyroid cancer," EndocrineRelated Cancer, vol. 12, no. 2, pp. 245-262, 2005.

[16] P. K. Paik, M. E. Arcila, M. Fara et al., "Clinical characteristics of patients with lung adenocarcinomas harboring BRAF mutations," Journal of Clinical Oncology, vol. 29, no. 15, pp. 20462051, 2011.

[17] M. Ilie, E. Long, V. Hofman et al., "Diagnostic value of immunohistochemistry for the detection of the $B R A F^{V 600 E}$ mutation in primary lung adenocarcinoma Caucasian patients," Annals of Oncology, vol. 24, no. 3, pp. 742-748, 2013.

[18] M. Kobayashi, M. Sonobe, T. Takahashi et al., "Clinical significance of $B R A F$ gene mutations in patients with non-small cell lung cancer," Anticancer Research, vol. 31, no. 12, pp. 46194623, 2011.

[19] H. Sasaki, S. Shimizu, Y. Tani et al., "Usefulness of immunohistochemistry for the detection of the BRAF V600E mutation in Japanese lung adenocarcinoma," Lung Cancer, vol. 82, no. 1, pp. 51-54, 2013.

[20] D. Chen, L. Q. Zhang, J. F. Huang et al., "BRAF mutations in patients with non-small cell lung cancer: a systematic review and meta-analysis," PLoS One, vol. 9, no. 6, pp. e101354e101357, 2014.

[21] P. P. Luk, B. Yu, C. C. Ng et al., "BRAF mutations in non-small cell lung cancer," Translational Lung Cancer Research, vol. 4, no. 2, pp. 142-148, 2015.

[22] Z. Li, L. Jiang, H. Bai et al., "Prevalence and clinical significance of BRAF V600E in Chinese patients with lung adenocarcinoma," Thoracic Cancer, vol. 6, no. 3, pp. 269-274, 2015.

[23] C. A. Pratilas, A. J. Hanrahan, E. Halilovic et al., "Genetic predictors of MEK dependence in non-small cell lung cancer," Cancer Research, vol. 68, no. 22, pp. 9375-9383, 2008.

[24] S. A. Yousem, M. Nikiforova, and Y. Nikiforov, "The histopathology of BRAF-V600E-mutated lung adenocarcinoma," The American Journal of Surgical Pathology, vol. 32, no. 9, pp. 1317-1321, 2008.

[25] S. Cardarella, A. Ogino, M. Nishino et al., "Clinical, pathologic, and biologic features associated with BRAF mutations in nonsmall cell lung cancer," Clinical Cancer Research, vol. 19, no. 16, pp. 4532-4540, 2013.
[26] M. F. Kalady, K. L. DeJulius, J. A. Sanchez et al., "BRAF mutations in colorectal cancer are associated with distinct clinical characteristics and worse prognosis," Diseases of the Colon and Rectum, vol. 55, no. 2, pp. 128-133, 2012.

[27] J. Tol, I. D. Nagtegaal, and C. J. A. Punt, "BRAF mutation in metastatic colorectal cancer," The New England Journal of Medicine, vol. 361, no. 1, pp. 98-99, 2009.

[28] C. H. Gow, M. S. Hsieh, Y. T. Lin, Y. N. Liu, and J. Y. Shih, "Validation of Immunohistochemistry for the Detection of BRAF V600E-Mutated Lung Adenocarcinomas," Cancers, vol. 11, no. 6, p. 866, 2019.

[29] L. Schirosi, S. Strippoli, F. Gaudio et al., "Is immunohistochemistry of BRAF V600E useful as a screening tool and during progression disease of melanoma patients?," BMC Cancer, vol. 16, no. 1, p. 905, 2016.

[30] K. Dvorak, B. Aggeler, J. Palting, P. McKelvie, A. Ruszkiewicz, and P. Waring, "Immunohistochemistry with the anti-BRAF V600E (VE1) antibody: impact of pre- analytical conditions and concordance with DNA sequencing in colorectal and papillary thyroid carcinoma," Pathology, vol. 46, no. 6, pp. 509517,2014

[31] F. E. Kombak, N. Ozkan, M. Ugurlu, and H. Kaya, "BRAFV600E immunohistochemistry in papillary thyroid carcinomas: relationship between clinical and morphological parameters," Turkish Journal of Pathology, vol. 35, no. 2, pp. 83-91, 2019.

[32] J. R. Bledsoe, M. Kamionek, and M. Mino-Kenudson, "BRAF V600E immunohistochemistry is reliable in primary \& metastatic colorectal carcinoma regardless of treatment status and shows high intratumoral homogeneity," The American Journal of Surgical Pathology, vol. 38, no. 10, pp. 1418-1428, 2014.

[33] K. Flaherty, I. Puzanov, J. Sosman et al., "Phase I study of PLX4032: proof of concept for V600E BRAF mutation as a therapeutic target in human cancer," Journal of Clinical Oncology, vol. 27, no. 461s, 2009.

[34] R. Kefford, H. Arkenau, M. P. Brown et al., "Phase I/II study of GSK2118436, a selective inhibitor of oncogenic mutant BRAF kinase, in patients with metastatic melanoma and other solid tumors," Journal of Clinical Oncology, vol. 28, Supplement 15, p. $8503,2010$.

[35] D. A. Heideman, I. Lurkin, M. Doeleman et al., "KRAS and $B R A F$ mutation analysis in routine molecular diagnostics : comparison of three testing methods on formalin-fixed, paraffin-embedded tumor-derived DNA," The Journal of Molecular Diagnostics, vol. 14, no. 3, pp. 247-255, 2012.

[36] D. Capper, A. S. Berghoff, M. Magerle et al., "Immunohistochemical testing of BRAF V600E status in 1,120 tumor tissue samples of patients with brain metastases," Acta Neuropathologica, vol. 123, no. 2, pp. 223-233, 2012.

[37] D. Capper, M. Preusser, A. Habel et al., "Assessment of BRAF V600E mutation status by immunohistochemistry with a mutation-specific monoclonal antibody," Acta Neuropathologica, vol. 122, no. 1, pp. 11-19, 2011.

[38] M. Ilie and P. Hofman, "Pitfalls in lung cancer molecular pathology: how to limit them in routine practice?," Current Medicinal Chemistry, vol. 19, no. 16, pp. 2638-2651, 2012. 


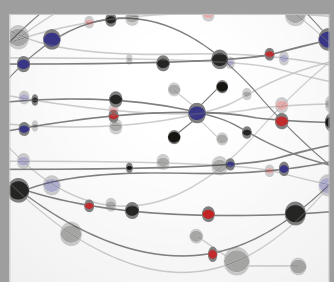

The Scientific World Journal
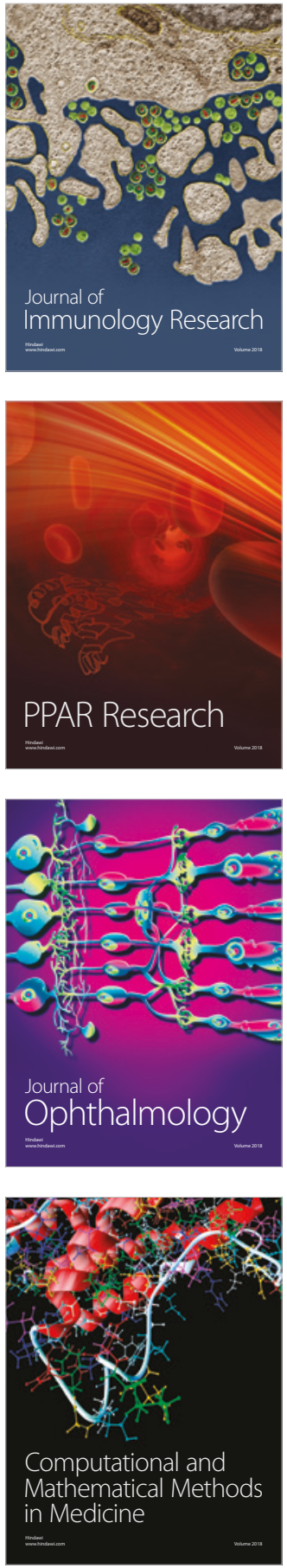

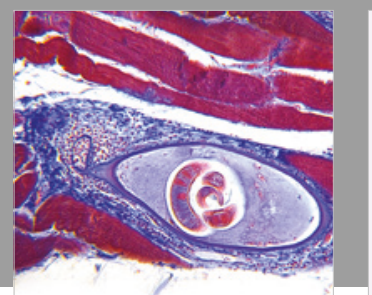

Gastroenterology Research and Practice

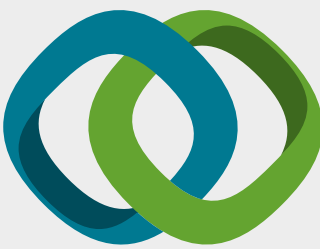

\section{Hindawi}

Submit your manuscripts at

www.hindawi.com
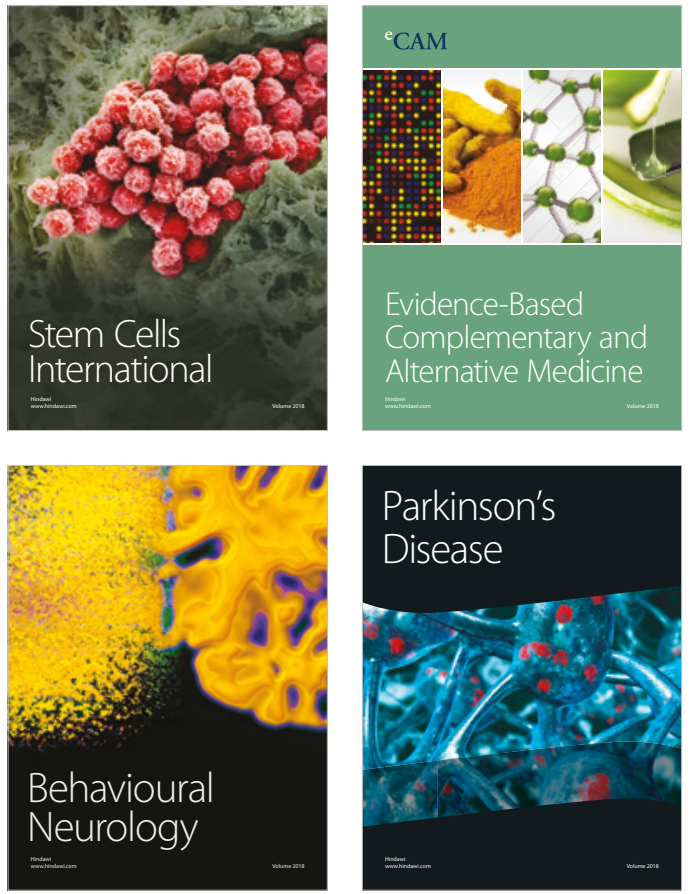

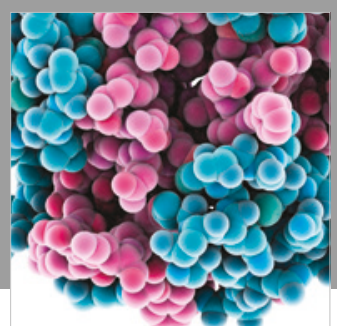

ournal of

Diabetes Research

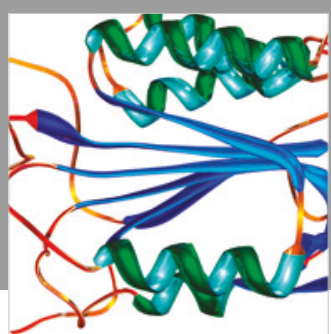

Disease Markers
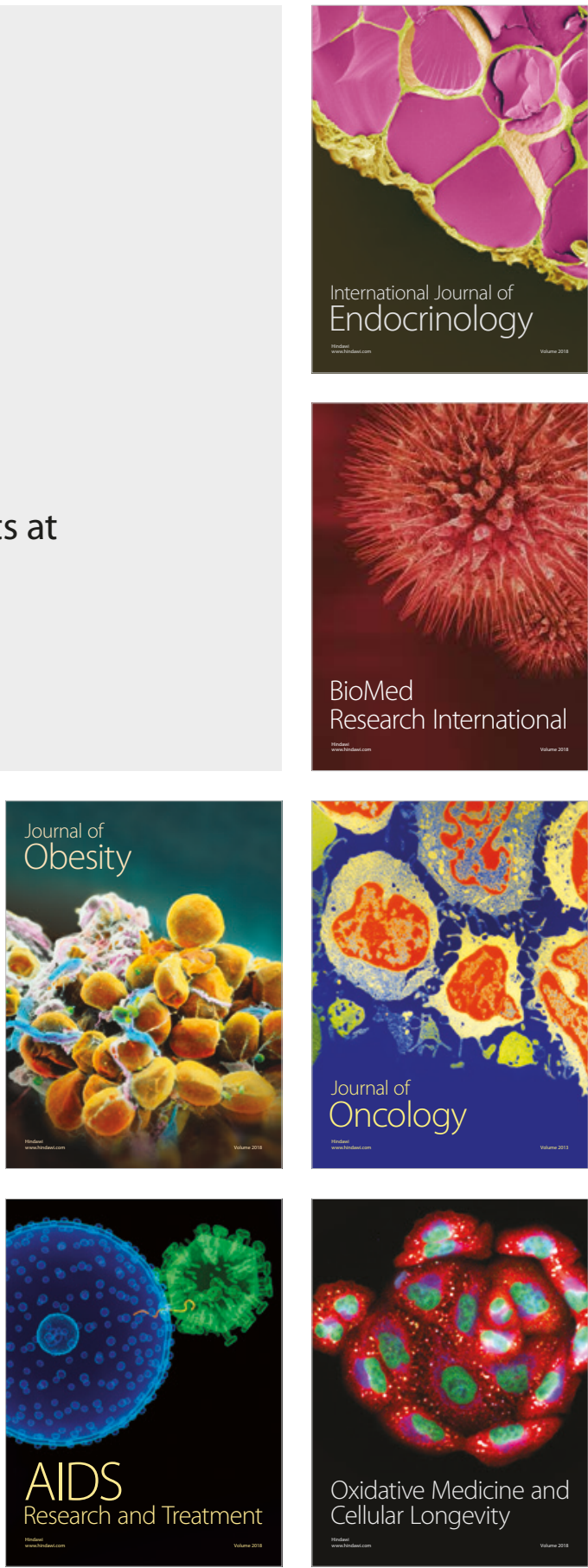